framum

Sociológico

\section{Forum Sociológico}

Série II

$27 \mid 2015$

Mobilidade científica \& imigração qualificada

Solé, Carlota ; Parella, Sonia ; Petroff, Alisa (Coords.) (2014), Las migraciones bolivianas en la encrucijada interdisciplinar evolución, cambios y tendencias

\title{
Cecilia Melella
}

\section{OpenEdition}

\section{Journals}

Edição electrónica

URL: https://journals.openedition.org/sociologico/1321

DOI: 10.4000/sociologico.1321

ISSN: 2182-7427

Editora

CICS.NOVA - Centro Interdisciplinar de Ciências Sociais da Universidade Nova de Lisboa

Edição impressa

Data de publição: 21 dezembro 2015

Paginação: 101-102

ISSN: 0872-8380

Refêrencia eletrónica

Cecilia Melella, «Solé, Carlota ; Parella, Sonia ; Petroff, Alisa (Coords.) (2014), Las migraciones bolivianas en la encrucijada interdisciplinar evolución, cambios y tendencias», Forum Sociológico [Online], 27 | 2015, posto online no dia 28 maio 2016, consultado o 31 março 2022. URL: http:// journals.openedition.org/sociologico/1321 ; DOI: https://doi.org/10.4000/sociologico.1321 


\title{
Solé, Carlota; Parella, Sonia; Petroff, Alisa (Coords.) (2014), Las migraciones bolivianas en la encrucijada interdisciplinar: evolución, cambios y tendencias, Coléccion Focus on International Migration no 1 , Editorial: Universitat Autónoma de Barcelona y Centre d' Estudis I Recerca en Migracions
}

\author{
Cecilia Melella \\ Instituto Multidisciplinario de Historia y Ciencias Humanas (IMHICIHU)/Consejo Nacional de Investigaciones Científicas \\ y Técnicas (CONICET) y Universidad de Buenos Aires
}

La obra colectiva "Las migraciones bolivianas en la encrucijada interdisciplinar: evolución, cambios y tendencias" (2014) constituye el primer número de una colección de monografías titulada "Focus on international Migration", editada por el Centre d' Estudis I Recerca en Migracions (CER) de la Universidad Autónoma de Barcelona bajo el formato e-book. En principio, resulta necesario subrayar que la migración boliviana constituye uno de los primordiales flujos migratorios internacionales hacia mercados laborales de países fronterizos, norteamericanos y europeos (en especial España). Como se destaca en este volumen, además de la dinámica constitutiva de la historia de ese país andino, la originalidad del fenómeno reside en la intensidad y las particularidades que adquieren estos flujos en un contexto de globalización y de creciente proliferación de vínculos transnacionales y multi-locales que caracterizan las migraciones contemporáneas. Los textos que integran esta compilación son producto de un largo proceso de debate en distintos espacios de discusión académica. Reúne los trabajos de un conjunto de investigadores e investigadoras que, desde diversas disciplinas como la sociología, la geografía, la historia y la demografía, y desde diferentes aproximaciones metodológicas han abordado el estudio de las migraciones bolivianas y sus impactos. A partir de estudios de caso llevados a cabo en diferentes contextos, los autores cubren un espectro geográfico amplio y avanzan hacia una comprensión trasnacional de las dinámicas migratorias.

El libro consta de seis capítulos y un apartado de conclusiones y reflexiones finales. En el Capítulo 1: "Bolivia, historia de migraciones: pasado y presente", Marcela Tapia (Investigadora de la Universidad Arturo Prat de Chile) revisa la historia migratoria de Bolivia en el contexto latinoamericano e internacional. Parte de una concepción holística con relación a los procesos migratorios interregionales y extra-regionales que definen las dinámicas migratorias bolivianas. No obstante, la minuciosidad del análisis histórico permite explicar la configuración actual del país andino y su constitución como foco emisor de migrantes.

El Capítulo 2: "El impacto de las migraciones cochabambinas en el marco de las transformaciones globales de las migraciones", fue elaborado por Carmen Ledo (Universidad Católica de Bolivia), Isabel Yepez (Universidad Católica de Lovaina) y Jean Michel Lafleur (Universidad de Lieja). A partir de la explotación de los datos de una macro-encuesta realizada por el Centro de Planificación y Gestión de la ciudad de Cochabamba (CEPLAG) en marzo de 2009, los autores elaboraron un apartado que recoge las características socio-demográficas de los migrantes bolivianos procedentes de la ciudad de Cochabamba. A partir de la información estadística se construyó el perfil de los migrantes, los principales destinos a los que viajan, los cambios en su constitución familiar, el uso de los medios de comunicación transnacionales y la posibilidad de participación política en el origen y en el destino.

El Capítulo 3: "Territorios bolivianos en las metrópolis españolas: Madrid y Barcelona" a cargo de Virginie Baby-Collin (Universidad de Marsella), Lucile Medina (Universidad de Montpellier), Naik Miret (Universidad de Poitiers) y Susana Sassone (CONICET, Argentina) y el Capítulo 4: "La inmigración boliviana en la Argentina: Lógicas geográficas de la difusión territorial y metropolización" realizado por Genevieve Cortés (Universidad de Montpellier) y Susana Sassone, exponen dos casos que exponen los modos de inscripción territorial de la migración boliviana en tres grandes metrópolis como Madrid, Barcelona y Buenos Aires. Para las autoras, las diferentes inscripciones territoriales en estas magnánimas urbes revelan formas de inserción social y modos de vida específicos del colectivo boliviano en el 
contexto metropolitano. Estas formas o estrategias, como la capacidad para generar redes o visibilizarse, conforman de patrones de territorialización que se han ido forjando a lo largo de los años.

El Capítulo 5: "Una aproximación tipológica del empresariado inmigrante transnacional de origen boliviano en España" de Leonardo Cavalcanti (Centro de Investigaciones y Pos-graduación sobre las Américas, CEPPAC de Brasilia) aborda el análisis de las prácticas transnacionales de carácter económico desde el estudio del empresariado transnacional boliviano afincado en España. La tesis de Cavalcani radica en que el empresariado inmigrante conforma una categoría analítica que permite vislumbrar la dimensión transnacional de esta migración, pues el fenómeno migratorio instituye la principal fuente de ingresos y contribuye de diferentes formas a la sociedad de origen y a la de destino.

El Capítulo 6: "El retorno cíclico boliviano: control y libertad en los proyectos de movilidad entre España y Bolivia" de Leonardo de la Torre (Universidad Autónoma de Barcelona) estudia las dinámicas de retorno de la migración boliviana residente en España. De la Torre afirma que la movilidad compone una particularidad del pueblo boliviano que se puede remontar al período pre-colonial y pre-incaico. A partir del concepto de "habitus migratorio boliviano" esbozada por Alfonso Hinojosa, De la Torre se pregunta por el peso de esta categoría a la hora de poner en juego negociaciones para a articular el retorno por parte de los migrantes de este país andino.

Finalmente, Sonia Parella y Alisa Petroff (Universidad Autónoma de Barcelona) concluyen que las aportaciones teórico-metodológicas y empíricas de la obra ponen en relieve el potencial de un abordaje interdisciplinario a la hora de estudiar las migraciones en contextos de transnacionalismo. En primer lugar, desatacan la relevancia del enfoque histórico dentro del campo migratorio como uno de los ejes fundamentales que recorren el libro. Asimismo, ponen en valor el protagonismo del espacio y las formas de territorialidad que admiten la superación de una visión meramente física y lo comprenden como "un producto social que se alimenta a partir de capitales y recursos que circulan a través de redes étnicas y sociales" (Parella y Petroff, 2014: 152) que nos hablan de las experiencias concretas y de las representaciones de los migrantes.

En tercer lugar, esta obra evidencia la necesidad de construcción de estrategias analíticas y metodológicas multi e interdisciplinarias que contemplen las metodologías múltiples y los análisis comparativos. Este enfoque pone de manifiesto que los procesos migratorios se leen de manera distinta según cada disciplina y pertenencia de los investigadores condición que, lejos de convertirse en un inconveniente, posibilita la concreción de una respuesta a la complejidad del fenómeno migratorio basada en la confluencia de metodologías y técnicas de distintos orígenes.

Por último, se recalca la importancia de la perspectiva transnacional como herramienta teórica, epistemológica y metodológica que faculta la comprensión de las migraciones -en nuestro caso bolivianas- de manera múltiple y exhaustiva. Asimismo, la obra destaca que la incorporación de la perspectiva transnacional para el análisis de las migraciones internacionales resulta imprescindible a la hora de proporcionar propuestas de políticas públicas en distintos ámbitos y de reflexionar sobre el papel que debe asumir el Estado. Ello incluye tanto el apoyo a personas migrantes y sus comunidades, con el fin de avanzar en el desarrollo familiar y comunitario en zonas emisoras, como la promoción de marcos políticos en las sociedades de destino que consigan aunar la multiplicidad de pertenencias e identidades para la conformación de sociedades más justas, inclusivas e igualitarias.

Recebido a 05/10/2015. Aceite para publicação a 05/12/2015.

Cecilia Melella (cemelella@gmail.com). Instituto Multidisciplinario de Historia y Ciencias Humanas (IMHICIHU)/ /Consejo Nacional de Investigaciones Científicas y Técnicas (CONICET) y Universidad de Buenos Aires. Manzoni 197 6to piso depto A, 1407 Ciudad Autónoma de Buenos Aires, Argentina. 